\title{
Influence of the initial sugar concentration and supplementation with yeast extract on the succinic acid fermentation from lactose based medium
}

\author{
Christiane Terboven 1, Christian Abendroth 2,3, Janin Laumer ${ }^{1}$, Christiane Herrmann ${ }^{4}$, Roland Schneider 4 , Patrice \\ Ramm ${ }^{5}$, Joachim Venus ${ }^{4}$, Matthias Plöchl 1,* \\ 1 BioenergieberatungBornim (B3), Max-Eyth-Allee 101, 14469 Potsdam, Germany; ct@b3-bornim.de (C.T.); \\ j1@b3-bornim.de (J.L.); mp@b3-bornim.de (M.P.) \\ 2 Institute of Waste Management and Circular Economy, Technische Universität Dresden, 01796 Pirna, \\ Germany; christian.abendroth@tu-dresden.de (C.A.) \\ 3 Robert Boyle Institute e. V., Im Steinfeld 10, 07751 Jena, Germany \\ 4 Leibniz Institute for Agricultural Engineering and Bioeconomy (ATB), Max-Eyth-Allee 100, 14469 Potsdam, \\ Germany; cherrmann@atb-potsdam.de (C.H.); rschneider@atb-potsdam.de (R.S.); jvenus@atb-potsdam.de \\ (J.V.) \\ 5 Institute of Agricultural and Urban Ecological Projects affiliated to Berlin Humboldt University (IASP), \\ Philippstr. 13, 10115 Berlin, Germany; patrice.ramm@iasp.hu-berlin.de (P.R.) \\ * Correspondence: mp@b3-bornim.de
}

\begin{abstract}
The aim of this study was to investigate succinic acid production from lactose concentrate, a by-product of cheese-making, using Actinobacillus succinogenes and Basfia succiniciproducens. Although the capability of these strains to metabolize different sugars is already known, their application in the conversion of lactose bears high potential for optimization. With regard to $B$. succiniciproducens this approach is completely novel. In particular the influence of the mediums sugar concentration and its supplementation with yeast extract to prevent a lack of proteins and vitamins were examined. Lactose based media containing sugar concentrations between 20 and 65 $\mathrm{g} \mathrm{L}^{-1}$ and $5 \mathrm{~g} \mathrm{~L}^{-1}$ yeast extract were fermented, whereby both strains showed comparable performances. The best results in succinic acid yield and acid concentration, $0.57 \mathrm{~g} \mathrm{~g}^{-1}$ initial sugar and $23 \mathrm{~g} \mathrm{~L}^{-1}$, were achieved at an initial sugar concentration of $43 \mathrm{~g} \mathrm{~L}^{-1}$. The necessity of yeast extract was demonstrated using the sugar optimized medium without supplementation. As a result, yield and concentration of succinic acid dropped to $0.34 \mathrm{~g} \mathrm{~g}^{-1}$ and $13 \mathrm{~g} \mathrm{~L}^{-1}$, the sugar consumption decreased from more than 99 to less than $55 \%$. Therefore the supplementation amount of $5 \mathrm{~g} \mathrm{~L}^{-1}$ yeast extract can be regarded as well-balanced.
\end{abstract}

Keywords: Actinobacillus succinogenes; Basfia succiniciproducens; succinic acid; lactose concentrate; yeast extract; platform chemical

\section{Introduction}

Succinic acid is a volatile fatty acid of high industrial interest, especially in fine chemistry, where it can be used as a platform chemical, for example in food and pharmaceutical industries [1], or for the production of biopolymers [2]. The production of biopolymers based on succinic acid might be a good alternative to conventional plastics based on fossil oil [3].

In 2013, $38.000 \mathrm{t}$ of succinic acid with a market value of $\$ 108$ million were produced bio-based by microbial fermentation. Bio-based succinic acid is a fast-growing market with an estimated potential of $\$ 7$ to 10 billion [3]. To satisfy the demand on bio-based succinic acid, large amounts of biomass are needed. In regard to the recent 'food versus fuel' discussion [4], organic residues and lignocellulosic biomass, representing the most abundant renewable organic sources on earth [5], should be used for the production of bio-based chemicals, such as succinic acid. In recent studies, succinic acid fermentations 
from the organic fraction of municipal solid waste [6], sugarcane bagasse [7], carob pods [8], corn stover [9], and straw [10] were investigated, using the succinogenic bacterial strains A. succinogenes or B. succiniciproducens.

There are several metabolic pathways known that are capable of succinic acid synthesis and exist in different types of microorganisms. Succinic acid is a metabolite typically occurring in all living organisms in the tricarboxylic acid cycle (TCA), where it is produced in the presence of oxygen (oxidative TCA). However, succinic acid can also be produced under anaerobic conditions utilizing the reductive TCA pathway [11]. The reductive pathway is a promising approach for succinic acid fermentation, as it allows the incorporation of carbon dioxide in degradation reactions with 6-carbon sugars [11]. Consequently, succinic acid fermentation could be used as a method to reduce the amount of industrial carbon dioxide emissions. The possibility to connect industrially produced carbon dioxide and succinic acid fermentation has been demonstrated, for example by [12] and [13].

In the past, succinic acid was synthesized by hydrogenation of maleic anhydride, a chemical produced from fossil oil [11]. In contrast, the discovery and utilization of succinic acid yielding bacteria, such as A. succinogenes [14] or B. succiniciproducens [15], allows the bio-based production of succinic acid by microbial fermentation, which is already applied on industrial scale [11].

However, in spite of the existence of industrial scale applications of succinogenic bacteria, several questions remain unsolved. Especially the fermentation of substrates which are based on different biological residues bears high potential for optimization. A promising low-cost residue for microbial fermentation is whey [16], since its applicability has already been demonstrated [17-19]. Whey can also serve for the production of protein concentrates, which are used as ingredients in sports beverages and special nutritional products [20]. The residue of the protein separation is a lactose rich whey fraction; concentrated by evaporation, this whey fraction turns into lactose concentrate. The use of lactose based substrates, such as whey or lactose concentrate, offers the advantage that the succinic acid fermentation with $A$. succinogenes is possible without pretreatment by enzymatic hydrolysis because this strain is able to utilize glucose, galactose and lactose [14]. Similar to A. succinogenes, B. succiniciproducens is capable of utilizing a diverse range of sugars, e. g. glucose, galactose, xylose, mannose and sucrose [15]. Although the fermentation of multiple sugars by B. succiniciproducens is described in the literature, the authors of the present study are not aware of any studies dealing with it in respect to lactose.

Besides a carbon source, bacteria need proteins and vitamins for an efficient metabolism [16]. In respect to $A$. succinogenes or B. succiniciproducens, an unbalanced ratio of these nutrients might decrease succinic acid productivity. Yeast extract is often used for supplementation of carbohydrate-rich media since it contains high amounts of proteins and vitamins $[7,21,19]$. Because yeast extract represents a significant expenditure, the reduction of its application to the minimum level is an important measure to reduce the production costs of succinic acid [22,23].

According to a modelling approach performed by [24], an optimal synthetic medium for succinic acid fermentation should contain $84.6 \mathrm{~g} \mathrm{~L}^{-1}$ glucose and $14.5 \mathrm{~g} \mathrm{~L}^{-1}$ yeast extract. Consequently, the optimal initial glucose to yeast extract ratio is 5.8 . This assumption is supported by findings published by [25], who observed a limited succinic acid production at an initial glucose to yeast extract ratio of 7.5; the initial sugar concentration in the study from [25] was $75 \mathrm{~g} \mathrm{~L}^{-1}$.

Usually, the succinic acid fermentation is accompanied by the synthesis of multiple by-products such as acetic acid, formic acid and lactic acid [25]. In order to decrease the synthesis of by-products and to maximize the succinic acid yield, an adaptation of the fermentation process is needed. Moreover, with regard to the production of commercial usable polybutylene succinate, the reduction of by-products is extremely profitable because monocarboxylic acids act as chain stoppers for the polymerisation [26]. 
However and in particular in respect to lactose based medium, the dependencies between fermentation efficiency and nutrient composition as well as the optimal ratio of mono- and disaccharides present in the substrate, have not been discussed in detail so far and the presented work aims to close this gap.

The main objective of the present study was to improve the succinic acid productivity, using the two natural acid producers A. succinogenes 130Z (DSM 22257) and B. succiniciproducens (DSM 22022) for fermentation tests in batch mode. Moreover, and in respect to these two strains, lactose concentrate, generated from cheese whey, was used as feedstock and main compound of the fermentation media. The present study consisted of two experiments. During the first experiment the influence of the sugar concentration on the succinic acid productivity was assessed by applying sugar concentrations between 20 and $65 \mathrm{~g} \mathrm{~L}^{-1}$. Concerning the low protein content of the lactose concentrate and a presumable lack of vitamins, yeast extract was used for supplementation. In the second experiment, the necessity of the supplementation with yeast extract to increase the succinic acid yields was investigated. Based on the two described experimental approaches, the present study had the following objectives:

1. Determining the potential of a by-product from cheese-making, lactose concentrate, as feedstock for bio-based succinic acid production.

2. Comparing the succinic acid fermentation performance of A. succinogenes 130Z (DSM 22257) and B. succiniciproducens (DSM 22022).

3. Examining the effect of yeast extract in lactose based medium on the succinic acid production.

\section{Materials and Methods}

\subsection{Microbial strains and precultivation}

The A. succinogenes $130 Z$ (DSM 22257) and B. succiniciproducens (DSM 22022) were procured from the German Collection of Microorganisms and Cell Cultures $\mathrm{GmbH}$ (DSMZ). The bacterial strains were kept as cryogenic stocks at $-80^{\circ} \mathrm{C}$ in $50 \%$ glycerol aqueous solution. Precultures were produced by inoculation of $100 \mathrm{~mL}$ tryptic soy broth in shaker flasks within 24 hours. The used orbital shaker had an agitation speed of 150 $\mathrm{rpm}$. The flasks were heat sterilized at $121^{\circ} \mathrm{C}$ for $15 \mathrm{~min}$.

\subsection{Fermentation media}

Lactose concentrate, a by-product from cheese-making (Karwendel-Werke-Huber GmbH \& Co. KG, Buchloe, Germany), and yeast extract (Ohly KAT, Deutsche Hefewerke GmbH Nürnberg, Germany) were used for the preparation of different fermentation media. For the preparation of media, the lactose concentrate was diluted with water to adjust three different target sugar concentrations of 20,40 and $60 \pm 5 \mathrm{~g} \mathrm{~L}^{-1}$, the resulting media were called A, B and C. The media for the first experiment were enriched with yeast extract in a concentration of $5 \mathrm{~g} \mathrm{~L}^{-1}$. The dosage of yeast extract was indicated by the letter $\mathrm{Y}$, consequently these media were called $\mathrm{AY}, \mathrm{BY}$ and $\mathrm{C}_{\mathrm{Y}}$. Lactose concentrate and yeast extract were autoclaved separately at $121^{\circ} \mathrm{C}$ for 15 minutes and afterwards aseptically mixed. The second experiment was conducted with medium B, whereby the addition of yeast extract was omitted. Each fermentation was started by adding $100 \mathrm{~mL}$ preculture to $900 \mathrm{~mL}$ medium. Lactose concentrate, yeast extract and fermentation media were chemically characterized prior to their use.

\subsection{Experimental setup and operation}

Fermentations were carried out in batch mode utilizing a $3 \mathrm{~L}$ Biostat bioreactor system (Sartorius AG, Göttingen, Germany). The fermentations were conducted at a temperature of $37^{\circ} \mathrm{C}$ and a $\mathrm{pH}$ value of 6.7 . The $\mathrm{pH}$ value was automatically regulated by the addition of $5 \mathrm{~N} \mathrm{NaOH}$. Carbon dioxide was continuously sparged into the reactor with a flow rate of $0.2 \mathrm{~L} \mathrm{~min}^{-1}$. A double Rushton turbine was used for stirring with an agitation 
speed of $300 \mathrm{rpm}$. The initial volume of each fermentation batch, consisting of medium and preculture, was $1 \mathrm{~L}$. The impact of the initial sugar concentration on the production of succinic acid and by-products was examined during the first experiment. Therefore, a series of fermentation tests with either A. succinogenes or B. succiniciproducens was conducted with fermentation media $\mathrm{Ay}, \mathrm{B} y$ and $\mathrm{C} y$ respectively.

In a second experimental approach, it was investigated if a decrease in nitrogen in the medium affects the bacterial sugar consumption and hence the acid production. Therefore, fermentations were repeated with medium B without addition of yeast extract. The test duration of the second experiment amounted to 55 hours.

During all fermentations, sampling of fermentation medium was carried out regularly in order to characterize the production kinetics of succinic acid and by-products, such as acetic, formic and lactic acid. Moreover, the amount and the composition of residual saccharides were analyzed, too. Directly upon each sampling, the succinic acid producing bacteria were inactivated by heating a sample for 20 minutes at $95^{\circ} \mathrm{C}$.

\subsection{Analytical methods}

The concentrations of sugars and acids were obtained by high performance liquid chromatography (HPLC) using a ULTIMATE 3000 system (Thermo Fischer Scientific, Waltham, USA) with an Eurokat H column (300 mm X 8 mm X $10 \mu \mathrm{m}$, Knauer, Berlin, Germany) and a refractive index detector (Shodex RI-101, Showa Denko, Tokio, Japan). Peak areas and retention times were compared to standard solutions. The sugar standard solution contained glucose, galactose, fructose, arabinose and lactose. The components of the acid standard solution were succinic, acetic, formic and lactic acid. The HPLC analysis required a pretreatment of lactose concentrate, yeast extract and fermentation media. Contained sugars and acids were dissolved by a cold water extraction as described by [27]. The determination of the total Kjeldahl nitrogen content (TKN) was carried out employing a standard method [28]. The $\mathrm{pH}$ value was measured according to methods stated by $[29,30]$. The protein content was calculated from the TKN by multiplication with the factor 6.25 [29].

\subsection{Calculation of the fermentation parameters}

The results retrieved from fermentation experiments were evaluated by comparing the determined final succinic acid concentration and the calculated succinic acid yield with regard to the initial sugar concentration. The formation of by-products served as additional important parameter. The synthesis of the by-products was expressed as mass ratios between succinic acid and acetic, formic or lactic acid. The total concentration of sugar was determined as sum of mono- and disaccharides and given as equivalent of glucose. The sugar consumption was defined as the amount of converted sugar in relation to the amount of initial sugar. The loss of medium due to sampling was taken into account for the calculation of the acid yields, the mass ratio between succinic acid and by-products, and the sugar consumption.

\section{Results and Discussion}

\subsection{Feedstock and fermentation media}

The chemical characteristics of the applied lactose concentrate as well as of the supplemented yeast extract, analyzed in duplicates, are given in Table 1. 
Table 1. Chemical characteristics of lactose concentrate and yeast extract.

\begin{tabular}{lcc}
\hline \multicolumn{1}{c}{ Parameter } & Lactose concentrate & Yeast extract \\
\hline Sugar $\left(\mathrm{g} \mathrm{kg}^{-1}\right)^{\mathrm{a}}$ & $268.4 \pm 0.1$ & $6.6 \pm 0.2$ \\
Glucose $\left(\mathrm{g} \mathrm{kg}^{-1}\right)$ & $7.2 \pm 0.1$ & n.d. \\
Galactose $\left(\mathrm{g} \mathrm{kg}^{-1}\right)$ & $21.2 \pm 0.0$ & n.d. \\
Saccharose $\left(\mathrm{g} \mathrm{kg}^{-1}\right)^{\mathrm{a}}$ & n.d. & $6.6 \pm 0.2$ \\
Lactose $\left(\mathrm{g} \mathrm{kg}^{-1}\right)^{\mathrm{a}}$ & $240.0 \pm 0.0$ & n.d. \\
Protein $\left(\mathrm{g} \mathrm{kg}^{-1}\right)$ & $12.0 \pm 0.0$ & $722.5 \pm 13.8$ \\
Lactic acid $\left(\mathrm{g} \mathrm{kg}^{-1}\right)$ & $37.6 \pm 0.0$ & $24.3 \pm 0.7$ \\
\hline
\end{tabular}

n. d. not dectected, a regarded as glucose equivalents

The lactose concentrate had a sugar concentration of $268 \mathrm{~g} \mathrm{~kg}^{-1}$ with a lactose percentage of almost $90 \%$ and a protein content of $12 \mathrm{~g} \mathrm{~kg}^{-1}$. In comparison to the lactose concentrate, the protein content of the yeast extract was sixty times higher and had a value of $723 \mathrm{~g} \mathrm{~kg}^{-1}$. The average initial sugar concentration of the media enriched with yeast extract (Ay, By and $\mathrm{C}_{\mathrm{Y}}$ ) were 21, 43 and $64 \mathrm{~g} \mathrm{~L}^{-1}$, the maximum standard deviation was $1 \mathrm{~g}$ $\mathrm{L}^{-1}$. The initial protein concentration of the media ranged between 4.5 and $6.5 \mathrm{~g} \mathrm{~L}^{-1}$. About 56 to $79 \%$ of the protein content was supplied by the yeast extract, depending on its ratio. The mass ratio of initial sugar to yeast extract of the media amounted to 4, 8 or 9 and 13 (Ay, By and Cy). A limited succinic acid production can be expected for media showing an initial sugar to yeast extract ratio higher than 7.5 , as described in the introduction. Consequently, limited succinic acid production and sugar consumption were predicted for media BY and CY.

The average initial concentration of sugar in the yeast extract free medium $\mathrm{B}$ amounted to $39 \mathrm{~g} \mathrm{~L}^{-1}$. As for media $\mathrm{B}$ y and $\mathrm{CY}$, a decline in succinic acid yield was also very likely for medium B. Lactose concentrate and yeast extract contained lactic acid in concentrations of $37.6 \mathrm{~g} \mathrm{~kg}^{-1}$ and $24.3 \mathrm{~g} \mathrm{~kg}^{-1}$, shown in Table 1. Consequently, the average initial content of lactic acid in the media $\mathrm{Ay}, \mathrm{By}, \mathrm{B}$ and $\mathrm{C}_{\mathrm{y}}$ were $3,6,5$ and $9 \mathrm{~g} \mathrm{~L}^{-1}$.

\subsection{Optimizing the sugar concentration for A. succinogenes and B. succiniciproducens}

Results of the fermentation experiments with media AY, By and $C_{Y}$ are summarized in Table 2 for both strains, A. succinogenes and B. succiniciproducens. The highest yields of succinic acid were achieved with an average initial sugar concentration of $21 \mathrm{~g} \mathrm{~L}^{-1}$ (medium Ay). In that case the succinic acid production was comparable for both strains, showing yields of $0.65 \mathrm{~g}$ (A. succinogenes) and $0.64 \mathrm{~g}$ (B. succiniciproducens) per $\mathrm{g}$ initial sugar. Application of media By or Cy resulted in small differences in succinic acid yields of both strains. A. succinogenes achieved 0.57 (medium By) and 0.41 (medium $C_{Y}$ ) g succinic acid per $\mathrm{g}$ initial sugar, while B. succiniciproducens yields amounted to 0.54 (medium BY) and 0.33 (medium $C_{Y}$ ) $\mathrm{g} \mathrm{g}^{-1}$. In comparison to media $\mathrm{Ay}_{\mathrm{y}}$ yields were $14 \%$ and $43 \%$ lower for media BY and $C_{Y}$.

Table 2. Results of the succinic acid production by A. succinogenes and B. succiniciproducens from lactose concentrate.

\begin{tabular}{|c|c|c|c|c|c|c|c|c|}
\hline \multirow[b]{2}{*}{ Parameter $\backslash$ Medium } & \multicolumn{4}{|c|}{ A. succinogenes } & \multicolumn{4}{|c|}{ B. succiniciproducens } \\
\hline & Ay & BY & $\mathrm{CY}_{\mathrm{Y}}$ & B & Ay & BY & $\mathrm{CY}$ & B \\
\hline Initial sugar concentration $\left(\mathrm{g} \mathrm{L}^{-1}\right)$ & 21 & 43 & 63 & 38 & 20 & 42 & 65 & 40 \\
\hline Initial sugar to yeast extract ratio & 4 & 9 & 13 & - & 4 & 8 & 13 & - \\
\hline Fermentation duration (h) & 19 & 46 & 47 & 55 & 20 & 46 & 47 & 54 \\
\hline Final succinic acid concentration $\left(\mathrm{g} \mathrm{L}^{-1}\right)$ & 13.0 & 22.8 & 24.0 & 13.3 & 12.4 & 21.6 & 19.5 & 13.3 \\
\hline Yield of succinic acid $\left(\mathrm{g} \mathrm{g}^{-1}\right)$ & 0.65 & 0.57 & 0.41 & 0.34 & 0.64 & 0.54 & 0.33 & 0.34 \\
\hline Residual sugar concentration $\left(\mathrm{g} \mathrm{L}^{-1}\right)$ & 0.2 & 0.3 & 12.9 & 16.1 & 0.0 & 0.2 & 17.8 & 17.9 \\
\hline Sugar consumption $(\%)$ & 99.2 & 99.8 & 75.6 & 53.8 & 100.0 & 99.7 & 68.1 & 50.9 \\
\hline Succinic acid to acetic acid ratio & $1: 0.43$ & $1: 40$ & $1: 42$ & $1: 0.37$ & $1: 35$ & $1: 30$ & $1: 32$ & $1: 29$ \\
\hline
\end{tabular}


Final succinic acid concentrations of $13.0 \mathrm{~g} \mathrm{~L}^{-1}$ (A. succinogenes) and $12.4 \mathrm{~g} \mathrm{~L}^{-1}$ (B. succiniciproducens) were measured at the end of fermentation trials with medium $A$ r. The increase of the average initial sugar concentration from $21 \mathrm{~g} \mathrm{~L}^{-1}$ (medium $\mathrm{Ar}$ ) to $43 \mathrm{~g}^{-1}$ (medium By) strongly enhanced the succinic acid production in respect to its final concentration, but at the expense of the yield. After 46 hours of fermentation with medium $\mathrm{By}$, the concentrations of succinic acid reached $22.8 \mathrm{~g} \mathrm{~L}^{-1}$ for A. succinogenes and $21.6 \mathrm{~g} \mathrm{~L}^{-1}$ for B. succiniciproducens, respectively. The course of succinic acid production during fermentation is exemplarily shown for A. succinogenes in Figure 1.
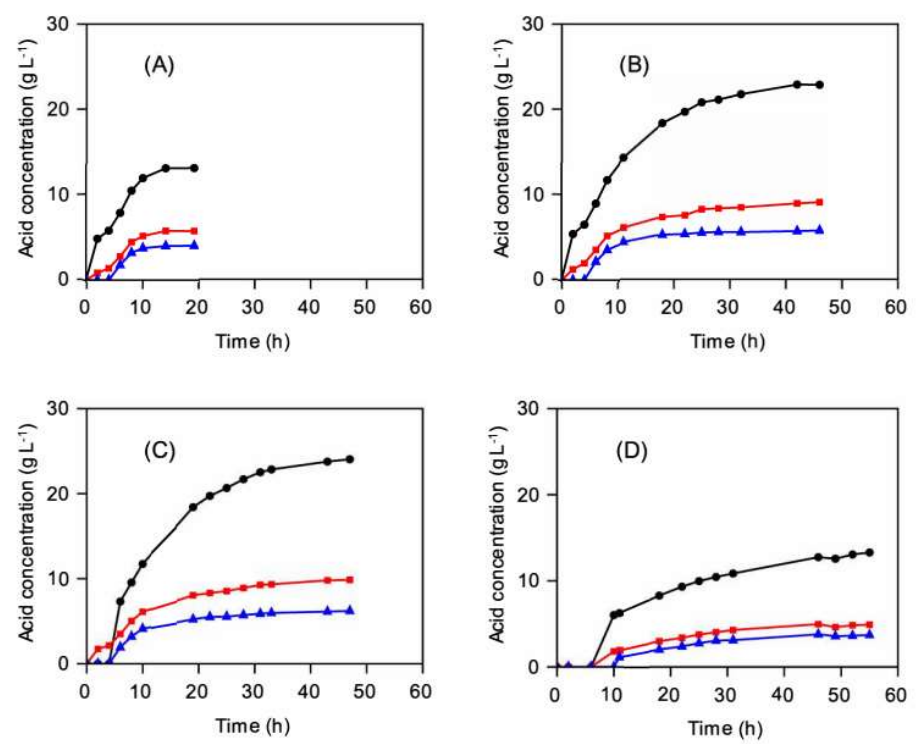

Figure 1. Acid production during fermentation with A. succinogenes, medium $\mathrm{Ay}(\mathrm{A})$, medium $\mathrm{BY}$ (B), medium $C_{Y}(C)$, medium B (D), concentration of succinic acid (black, circle), acetic acid (red, square) and formic acid (blue, triangle,).

Further increase of the average initial sugar concentration to $64 \mathrm{~g} \mathrm{~L}^{-1}$ (medium $\mathrm{Cr}$ ) was not effective since it caused only a small increase (A. succinogenes) or even a small decrease (B. succiniciproducens) of the succinic acid production compared to medium Br. This observation was accompanied by a sharp decrease of the succinic acid yield from 0.65 to $0.41 \mathrm{~g} \mathrm{~g}^{-1}$ initial sugar (A. succinogenes) and from 0.64 to $0.33 \mathrm{~g} \mathrm{~g}^{-1}$ initial sugar (B. succiniciproducens) compared to medium Ar. Although not tested with lactose, a similar effect was observed for glucose by [25]. In the respective study, a succinic acid concentration of $41 \mathrm{~g} \mathrm{~L}^{-1}$ was reached by fermentation of a synthetic medium with a glucose concentration of $51 \mathrm{~g} \mathrm{~L}^{-1}$, further increase of the initial glucose concentration to 74 $\mathrm{g} \mathrm{L}^{-1}$ did not enhance the succinic acid production [25]. Besides negative effects on acid productivity caused by high initial sugar concentrations, a decrease of succinic acid yields might also be explained by an inhibitory effect of the acids produced during fermentation. [31] reported that the succinic acid production stopped when the concentration of the microbially produced acid mixture reached values of $45 \mathrm{~g} \mathrm{~L}^{-1}$. With $49 \mathrm{~g} \mathrm{~L}^{-1}$ (A. succinogenes) and $44 \mathrm{~g} \mathrm{~L}^{-1}$ (B. succiniciproducens) in the present study, fermentation of medium $\mathrm{Cr}_{\mathrm{r}}$ resulted in concentrations, which were in a similar range as described by [31]. Therefore, the lowered yield might have occurred due to product inhibition.

With regard to the succinic acid production potential, yields observed in this study during the fermentation of lactose concentrate are in a similar range as yields from other organic by-products that are stated in literature. [7] obtained a final succinic acid concentration of $23 \mathrm{~g} \mathrm{~L}^{-1}$ from hydrolyzed sugarcane bagasse (supplemented with yeast extract and minerals), where the initial sugar concentration (xylose) was $52 \mathrm{~g} \mathrm{~L}^{-1}$. [19] 
measured $28 \mathrm{~g} \mathrm{~L}^{-1}$ succinic acid after 48 hours of fermentation using a medium with an initial cheese whey concentration of $100 \mathrm{~g} \mathrm{~L}^{-1}$. [6] published a techno-economic case study of the succinic acid production from the organic fraction of municipal waste and calculated profitability indicators. The calculation was based on a succinic acid productivity of $0.89 \mathrm{~g} \mathrm{~L}^{-1} \mathrm{~h}^{-1}$ and a production capacity higher than $40,000 \mathrm{t}$ per year. From medium By a similar succinic acid productivity of $0.87 \mathrm{~g} \mathrm{~L}^{-1} \mathrm{~h}^{-1}$ was achieved during 23hour fermentation with $A$. succinogenes, the corresponding succinic acid yield was $0.50 \mathrm{~g}$ $\mathrm{g}^{-1}$. B. succiniciproducens reached the same productivity after 20 hours of fermentation, but there was a small decline in the succinic acid yield to $0.45 \mathrm{~g} \mathrm{~g}^{-1}$.

During the fermentation of media $A_{y}$ and $B_{Y}$, more than $99 \%$ of the contained sugars were converted. When applying the medium BY, a decline in the sugar consumption did not occur. This is surprising, as in comparison to the results obtained with medium Ay the conditions were less favorable in respect to initial sugar to yeast extract ratio (increase from 4 to 8 or 9 ).

In contrast to the efficient sugar conversion with medium $\mathrm{B} Y$, the sugar consumption decreased to less than $76 \%$ during the fermentation of medium $C_{Y}$. At the end of the fermentation trials, the (residual) sugar concentrations in medium $C_{\text {Y }}$ were $13 \mathrm{~g} \mathrm{~L}^{-1}(A$. succinogenes) and $18 \mathrm{~g} \mathrm{~L}^{-1}$ (B. succiniciproducens) with a galactose percentage of $81 \%$ and $80 \%$. Therefore, it may be assumed that both bacteria strains were capable to cleave lactose into the components glucose and galactose. Subsequently, glucose was rapidly utilized, and probably, the consumption of galactose was limited. This assumption is supported by results from previous studies. For example, while conducting succinic acid fermentations with media showing initial whey concentrations of 50 to $100 \mathrm{~g} \mathrm{~L}^{-1}$ and supplemented with minerals, peptone and yeast extract, [19] observed a fast consumption of glucose but a delay in the consumption of galactose, especially during the first 24 hours.

Apart from succinic acid, the main by-product of the succinic acid fermentations was acetic acid. The production of $1 \mathrm{~g}$ succinic acid with $A$. succinogenes from media $\mathrm{Ay}, \mathrm{B}$ y and CY was accompanied by the production of $0.42 \mathrm{~g}$ acetic acid on average (Table 2). In comparison to that, formic and lactic acid were formed at ratios of $0.27 \mathrm{~g}$ and $0.03 \mathrm{~g}$ per $\mathrm{g}$ succinic acid.

Formation of lactic acid occurred especially during the fermentation of medium $\mathrm{CY}_{\mathrm{Y}}$ with B. succiniciproducens. The final lactic acid concentration was $12 \mathrm{~g} \mathrm{~L}^{-1}$ and the final mass ratio between succinic and lactic acid reached values of $1: 0.26$. In comparison, after the fermentation of medium $C y$ with $A$. succinogenes the ratio was $1: 0.06$. The fermentation of a synthetic medium containing $60 \mathrm{~g} \mathrm{~L}^{-1}$ glucose and $6 \mathrm{~g} \mathrm{~L}^{-1}$ yeast extract with B. succiniciproducens conducted by [9] resulted in a comparable lactic acid concentration of $10 \mathrm{~g} \mathrm{~L}^{-1}$, the final mass ratio between succinic and lactic acid was $1: 0.35$.

\subsection{Yeast supplementation for optimization of succinic acid fermentation}

The aim of the second experiment was to find out, if the supplementation with yeast extract had a positive influence on the succinic acid production. To demonstrate the importance of nitrogen and vitamins contained in yeast extract, the experiment evaluated in section 3.2. was repeated without adding yeast extract (medium B). A sugar concentration of about $40 \mathrm{~g}$ per liter was applied, because it was determined as optimal from results of the previous experiment.

The fermentations with $A$. succinogenes and B. succiniciproducens led to identical succinic acid yields of $0.34 \mathrm{~g} \mathrm{~g}^{-1}$ initial sugar (Table 2). Within 55 hours the succinic acid concentration reached a value of $13.3 \mathrm{~g} \mathrm{~L}^{-1}$. Thus, the succinic acid production with medium B was about $40 \%$ lower compared to the same medium supplemented with yeast extract (BY). Moreover, the sugar consumption decreased sharply from more than $99 \%$ to $54 \%$ (A. succinogenes) and $51 \%$ (B. succiniciproducens), respectively.

Similar to the fermentation of medium $C_{Y}$, the degradation of galactose was limited during the fermentation of medium B. The residual sugar concentrations were 16 and 18 $\mathrm{g} \mathrm{L}^{-1}$ with galactose shares of $75 \%$ (A. succinogenes) and $67 \%$ (B. succiniciproducens). The 
negative effect of the lack of nutrients is exemplarily shown for A. succinogenes in Figure 2.
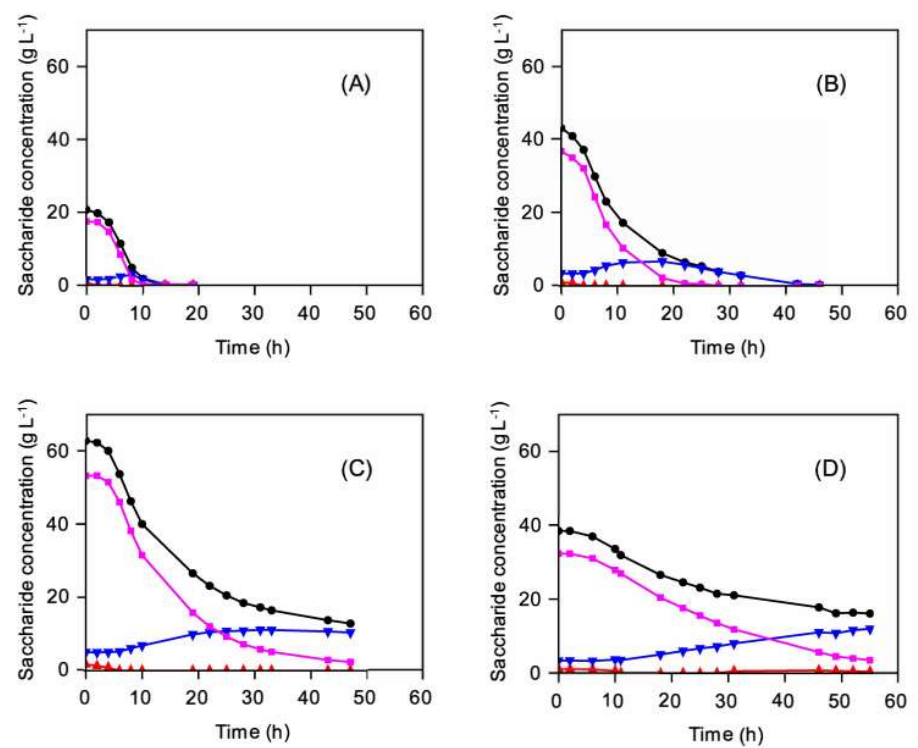

Figure 2. Sugar degradation during fermentation with A. succinogenes, medium $\mathrm{AY}(\mathrm{A})$, medium $\mathrm{B} Y$ (B), medium $\mathrm{CY}_{Y}(\mathrm{C})$, medium B (D), concentration of sugar (black, circle,), lactose (violet, square), glucose (red, upward-pointing triangle) and galactose (blue, downward-pointing triangle).

The results indicate a lack of protein or other essential nutrients, such as vitamins, that are contained in yeast extract. [32] determined a sugar consumption of only $65 \%$ during the fermentation of diluted pineapple juice showing an initial sugar concentration of $56 \mathrm{~g} \mathrm{~L}^{-1}$. [32] were able to increase the sugar consumption to $82 \%$ due to the supplementation with $5 \mathrm{~g} \mathrm{~L}^{-1}$ yeast extract and minerals. The resulting initial sugar to yeast extract ratio of 11 was even higher than the optimal ratio of 5.8 derived from the model verification of [24].

\section{Conclusions}

Lactose concentrate from cheese production is a very suitable feedstock for succinic acid production using $A$. succinogenes or B. succiniciproducens as converting microorganisms. A broad range of initial sugar concentrations from 20 to $65 \mathrm{~g} \mathrm{~L}^{-1}$ in the medium can be applied. Best performance was achieved at an initial sugar concentration of $43 \mathrm{~g} \mathrm{~L}$ ${ }^{1}$ for both the acid yield per initial sugar with $0.57 \mathrm{~g}$ per $\mathrm{g}$ initial sugar and the acid concentration with up to $23 \mathrm{~g} \mathrm{~L}^{-1}$. The supplementation with yeast extract appeared to be mandatory, since its absence resulted in lower succinic acid concentrations. A yeast extract concentration of $5 \mathrm{~g} \mathrm{~L}^{-1}$ proofed to be more than sufficient. Further investigation on the minimal concentration of yeast extract in the medium are recommended to increase the profitability of the process.

Author Contributions: Conceptualization, C.T. and J.L.; methodology, C.T., J.L. and R.S.; validation, C.T., M.P. and J.V.; formal analysis, C.T. and P.R.; investigation, C.T., J.L., and R.S.; resources, M.P., C.H. and J.V.; data curation, C.T. and R.S.; writing - original draft preparation, C.T., C.A. and P.R.; writing - review and editing, C.T., C.A.,C.H., P.R., J.V. and M.P.; visualization, C.T. and P.R.; supervision, M.P.; project administration, M.P.; funding acquisition, C.A. and M.P. All authors have read and agreed to the published version of the manuscript.

Funding: The research was funded by the Bundesministerium für Wirtschaft und Energie (BMWi) within the framework of the program "Zentrales Innovationsprogramm Mittelstand (ZIM)", grant numbers 16KN070127, 16KN070126 and 16KN070128. 
Data Availability Statement: The reported results are available upon request to the authors.

Acknowledgments: We give our special acknowledgements to the members of the chemicalanalytical lab of the Leibniz Institute for Agricultural Engineering and Bioeconomy for their ambitious support. Finally, we want to thank Olaf Luschnig from the BioEnergie Verbund e.V. for his organizational support.

Conflicts of Interest: The authors declare no conflict of interest.

\section{References}

1. Jiang, M.; Ma, J. Wu, M.; Liu, R.; Liang, L.; Xin, F.; Zhang, W.; Jia, H.; Dong, W. Progress of succinic acid production from renewable resources: Metabolic and fermentative strategies. Bioresour. Technol. 2017, 245, 1710-1717. https://doi.org/10.1016/j.biortech.2017.05.209

2. Ventorino, V.; Robertiello, A.; Viscardi, S.; Ambrosanio, A.; Faraco, V., Pepe, O. Bio-based chemical production from Arundo donax feedstock fermentation using Cosenzaea myxofaciens BPM1. BioRes. 2016, 11,6566-6581. https://doi.org/10.1007/s12155-017-9814-y

3. Taylor, R.; Nattrass, L.; Alberts, G.; Robson, P.; Chudziak. C.; Bauen, A. From the sugar platform to biofuels and biochemicals. Final report for the European Commission Directorate-General Energy N ${ }^{\circ}$ ENER/C2/423-2012/SI2.673791. Available online: https://ec.europa.eu/energy/sites/ener/files/documents/EC\%20Sugar\%20Platform\%20final\%20report.pdf (accessed on 27 April 2021).

4. Graham-Rowe, D. Agriculture: Beyond food versus fuel. The most controversial aspect of biofuels is the perceived competition for farmland. Will advances in biofuels and agriculture send this trade - off speeding towards the history books?. Nature 2011, 474, 6-8. https://doi.org/10.1038/474S06a

5. Da Silva, S.S.; Chandel, A.K.; Wickramasinghe, S.R.; Domínguez, J.M.G. Fermentative production of value-added products from lignocellulosic biomass. J. Biomed. Biotechnol. 2012, 826162. https://doi.org/10.1155/2012/826162

6. Ioannidou, S.M.; Pateraki, C.; Dimitrios, L.; Papapostolou, H.; Tsakona, M.; Vlysidis, A.; Kookos, I.K.; Koutinas, A. Sustainable production of bio-based chemicals and polymers via integrated biomass refining and bioprocessing in a circular bioeconomy context. Bioresour. Technol. 2020, 307, 123093.

7. Borges, E.R.; Pereira, N. Succinic acid production from sugarcane bagasse hemicellulose hydrolysate by Actinobacillus succinogenes. J. Ind. Microbiol. Biotechnol. 2011, 38, 1001-1011. https://doi.org/10.1007/s10295-010-0874-7

8. Carvalho, M.; Roca, C.; Reis, M.A.M., Improving succinic acid production by Actinobacillus succinogenes from raw industrial carob pods. Bioresour. Technol. 2016, 218, 491-497. https://doi.org/10.1016/j.biortech.2016.06.140

9. Salvachúa, D.; Smith, H.; St. John, P.C.; Mohagheghi, A.; Peterson, D.J.; Black, B.A.; Dowe, N.; Beckham, G.T. Succinic acid production from lignocellulosic hydrolysate by Basfia succiniciproducens. Bioresour. Technol. 2016, 214, 558-566. https://doi.org/10.1016/j.biortech.2016.05.018

10. Zheng, P.; Dong, J.J.; Sun, Z.H.; Ni, Y.; Fang, L. Fermentative production of succinic acid from straw hydrolysate by Actinobacillus succinogenes. Bioresour. Technol. 2009, 100, 2425-2429. https://doi.org/10.1016/j.biortech.2008.11.043

11. Nghiem, N.P.; Kleff, S.; Schwegmann, S. Succinic Acid: Technology Development and Commercialization. Fermentation 2017, 3, 26. https://doi.org/10.3390/fermentation3020026

12. Gunnarsson I.B.; Alvarado-Morales, M.; Angelidaki, I. Utilization of CO2 fixating bacterium Actinobacillus succinogenes $130 Z$ for simultaneous biogas upgrading and bio-succinic acid production. Environ. Sci. Technol. 2014, 48, 12464-12468. https://doi.org/10.1021/es504000h

13. Cimini, D.; Zaccariello, L.; D'Ambrosio, S.; Lama, L.; Ruoppolo, G.; Pepe, O.; Faraco, V.; Schiraldi, C.. Improved production of succinic acid from Basfia succiniciproducens growing on A. donax and process evaluation through material flow analysis. Biotechnol. Biofuels. 2019, 12, 22. https://doi.org/10.1186/s13068-019-1362-6

14. Guettler, M.V.; Rumler, D.; Jain M.K. Actinobacillus succinogenes sp. nov., a novel succinic-acid-producing strain from the bovine rumen. Int. J. Syst. Bacteriol. 1999, 49, 207-216. https://doi.org/10.1099/00207713-49-1-207

15. Kuhnert, P.; Scholten, E.; Haefner, S.; Mayor, D.; Frey, J. Basfia succiniciproducens gen. nov., sp. nov., a new member of the family Pasteurellaceae isolated from bovine rumen. Int. J. Syst. Evol. Microbiol. 2010, 60, 44-50. https://doi.org/10.1099/ijs.0.011809-0

16. Du, C.; Lin, S.K.C.; Koutinas, A.; Wang, R.; Webb, C. Succinic acid production from wheat using a biorefining strategy. Appl. Microbiol. Biotechnol. 2007, 76, 1263-1270. https://doi.org/10.1007/s00253-007-1113-7

17. Samuelov, N.S.; Datta, R.; Mahendra, K.J.; Zeikus, J.G. Whey fermentation by Anaerobiospirillum suciniciproducens for production of a succinate-based animal feed additive. Appl. Environ. Microbiol. 1999, 65, 2260-2263. https://doi.org/10.1128/AEM.65.5.2260-2263.1999

18. Longanesi, L.; Frascari, D.; Spagni, C.; DeWever, H.; Pinelli, D. Succinic acid production from cheese whey by biofilms of Actinobacillus succinogenes: packed bed bioreactor tests. J. Chem. Technol. Biotechnol. 2018, 93, 246-256. https://doi.org/10.1002/jctb.5347

19. Wan, C.; Li, Y.; Shahbazi, A.; Xiu, S. Succinic acid production from cheese whey using Actinobacillus succinogenes 130 Z. Appl. Biochem. Biotechnol. 2008, 145, 111-119. https://doi.org/10.1007/s12010-007-8031-0 
20. Huffman, L.M.; Harper, W.J. Maximizing the value of milk through separation technologies. J. Dairy Sci. 1999, 82, $2238-2244$. https://doi.org/10.3168/jds.S0022-0302(99)75471-8

21. Thuy, N.T.H.; Kongkaew, A.; Flood, A.; Boontawan, A. Fermentation and crystallization of succinic acid from Actinobacillus succinogenes ATCG55618 using fresh cassava root as the main substrate. Bioresour. Technol. 2017, 233, 342-352. https://doi.org/10.1016/j.biortech.2017.02.114

22. Bradfield, M.F.A.; Mohagheghi, A.; Salvachúa, D.; Smith, H.; Black, B.A.; Dowe, N.; Beckham, G.T.; Nicol, W. Continuous succinic acid production by Actinobacillus succinogenes on xylose-enriched hydrolysate. Biotechnol. Biofuels $2015,8,181$. https://doi.org/10.1186/s13068-015-0363-3

23. Chen, K.; Zang, H.; Miao, Y.; Wei, P.; Chen, J. Simultaneous saccharification and fermentation of acid-pretreated rapeseed meal for succinic acid production using Actininobacillus succinogenes, Enzyme Microb. Technol. 2011, 48, 339-344. https://doi.org/10.1016/j.enzmictec.2010.12.009

24. Zhu, L.W.; Wang, C.C.; Lia, R.S.; Li, H.M.; Wan, D.J.; Tang, Y.J. Actinobacillus succinogenes ATCC 55618 fermentation medium optimization for the production of succinic acid by response surface methodology. J. Biomed. Biotechnol. $2012,626137$. https://doi.org/10.1155/2012/626137

25. Lui, Y. P.; Zheng, P.; Sun, Z.H.; Ni, Y.; Dong, J.J.; Wei, P. Strategies of pH control and glucose-fed batch fermentation for production of succinic acid by Actinobacillus succinogenes CGMCC1593. J. Chem. Technol. Biotechnol. 2008, 83, 722-729. https://doi.org/10.1002/jctb.1862

26. Alexandri, M.; Vlysidis, A.; Papapostolou, H.; Tverezovskaya, O.; Tverezovskiy, V.; Kookos, I.K.; Koutinas, A. Downstream separation and purification of succinic acid from fermentation broths using spent sulphite liquor as feedstock. Sep. Purif. Technol. 2019, 209, 666-675. https://doi.org/10.1016/j.seppur.2018.08.061

27. Pleissner, D.; Neu, A.K.; Mehlmann, K.; Schneider, R.; Puerta-Quintero, G.I.; Venus, J. Fermentative lactic acid production from coffee pulp hydrolysate using Bacillus coagulans at laboratory and pilot scales. Bioresour. Technol. 2016, 218, 167-173. https://doi.org/10.1016/j.biortech.2016.06.078

28. DIN. DIN EN 25663:1993-11. Water quality; determination of Kjeldahl nitrogen; method after mineralization with selenium; DIN Deutsches Institut für Normung e. V.: Berlin, Germany, 1993.

29. VDLUFA. Method Book III - The Chemical analysis of foodstuffs, 3rd ed., including 1st - 8th supplement delivery 1976 - 2012 ; VDLUFA: Darmstadt, Germany, 2012.

30. VDLUFA. Method Book I - The examination of soils, 4th ed., including 1st - 7th supplement delivery 1991 - 2016; VDLUFA: Darmstadt, Germany, 2016.

31. Corona-González, R.I.; Bories, A.; González-Álvarez, V.; Pelayo-Ortiz, C. Kinetic study of succinic acid production by Actinobacillus succinogenes ZT-130. Process. Biochem. 2008, 43, 1047-1053. https://doi.org/10.1016/j.procbio.2008.05.011

32. Ferone, M.; Ercole, A.; Raganati, F.; Olivieri, G.; Salatino, P.; Marzocchella, A. Efficient succinic acid production from highsugars-content beverages by Actinobacillus succinogenes. Biotechnol. Prog. 2019, 35. https://doi.org/10.1002/btpr.2863 